For citation information on this paper please see
http://www.claisse.info/Publish.htm

\title{
PERMEABILITY AND PORE VOLUME OF CARBONATED CONCRETE
}

Peter A Claisse, Hanaa I Elsayad and Ibrahim G Shaaban.

\begin{abstract}
Carbonation is widely recognised as a significant cause of corrosion of reinforcement in concrete. However, in addition to the depassivation of the steel it has several other effects. This paper investigates the effect of carbonation on the permeability and pore structure of concrete. One of the most significant consequences of this effect is that it causes standard tests for durability to give misleading results.

Suitable test procedures for the measurement of porosity and permeability were chosen from a review of the available techniques. Samples of two concrete mixes with different water/cement ratios were each prepared with both wet and dry curing and exposed in a carbonation chamber for up to 140 days. The results show that carbonation reduces the permeability and porosity and indicate the extent of this reduction. The reduction was greatest in poor quality concrete.

When compared with the other effects of carbonation the reduction in permeability is seen to be similar to the reduction in electrical resistivity because this can also lead to misleading test results.
\end{abstract}

\section{INTRODUCTION}


Corrosion of reinforcement is a major cause of the deterioration of concrete structures. Carbonation is widely recognised as a significant factor in this corrosion process. The basic mechanism whereby atmospheric carbon dioxide reacts with components of the hydrated cement and destroys its alkalinity is well understood [1]. The chemistry of the pore solution is not, however, the only property of concrete which affects reinforcement corrosion. The transport properties of the concrete include permeability, diffusion, capillary suction, osmosis and electro-migration and have been shown to have a significant effect [2]. Transport properties affect the durability of concrete because they control the supply of aggressive species, such as chlorides, to the site of deterioration. This paper reports an investigation on the effect of carbonation on permeability and on porosity which has a significant influence on most of the transport properties.

\section{The Carbonation Process}

Carbonation of concrete is traditionally defined [3] as the chemical reaction between atmospheric carbon dioxide and the products of cement hydration particularly $\mathrm{Ca}(\mathrm{OH})_{2}$ in accordance with the reaction:

$\mathrm{Ca}(\mathrm{OH})_{2}+\mathrm{CO}_{2} \rightarrow \mathrm{CaCO}_{3}+\mathrm{H}_{2} \mathrm{O}$

However, it is now accepted [4] that the other hydration products (calcium silicate hydrate or CSH) and even the residual unhydrated cement compounds which are present in all concrete (namely tricalcium silicate $\left(\mathrm{C}_{3} \mathrm{~S}\right)$ and dicalcium silicate $\left.\left(\mathrm{C}_{2} \mathrm{~S}\right)\right)$ also react with $\mathrm{CO}_{2}$ as shown in the following reactions:

$\mathrm{CSH}+3 \mathrm{CO}_{2} \rightarrow\left(3 \mathrm{CaCO}_{3} \cdot 2 \mathrm{SiO}_{2} \cdot 3 \mathrm{H}_{2} \mathrm{O}\right)$

$\mathrm{C}_{3} \mathrm{~S}+3 \mathrm{CO}_{2}+v \mathrm{H}_{2} \mathrm{O} \rightarrow \mathrm{SiO}_{2} \cdot v \mathrm{H}_{2} \mathrm{O}+3 \mathrm{CaCO}_{3}$

$\mathrm{C}_{2} \mathrm{~S}+2 \mathrm{CO}_{2}+v \mathrm{H}_{2} \mathrm{O} \rightarrow \mathrm{SiO}_{2} \cdot v \mathrm{H}_{2} \mathrm{O}+2 \mathrm{CaCO}_{3}$

Carbonation [5] leads to a reduction in porosity of the exposed concrete surface because the volume of the reaction product $\left(\mathrm{CaCO}_{3}\right)$ exceeds that of the original reactants. Researchers have used this phenomenon to develop test techniques to evaluate the degree of carbonation based on air permeability measurements $[6,7,8]$. Pihlajavaara [9] published limited data on the effect of carbonation on porosity and pore size 
distribution of cement paste. Dewaele et. al. [10] examined the effect of carbonation on permeability and porosity of cement grout, but due to problems in the test set up only small carbonation depths were achieved within the time scale of the experimental program. The author cited no detailed study devoted to the effect of carbonation on the permeability and pore structure of concrete.

\section{Research Significance}

The aim of this work is to describe quantitatively the effect of carbonation on the air permeability and pore volume of typical concrete mixes. Concrete exposed to the atmosphere usually suffers from carbonation especially in moderately humid and hot climates. An understanding of the degree by which carbonation changes the microstructure of concrete is necessary for the interpretation of in-situ investigations which involve absorption measurements. Carbonation may lead to decrease in pore volume, giving the impression that such concrete is relatively impermeable. It is hoped that this study will allow researchers to take the effect of carbonation into account when assessing the absorption results from old concrete structures.

\section{EXPERIMENTAL PROCEDURES}

\section{Concrete materials and mix design}

All materials used conformed to the relevant Egyptian Standard Specifications. Two concrete mixes were used to prepare the test specimens. The mix proportions and average compressive strengths of the samples are shown in Table 1.

\section{Preparation of test specimens}


Two types of specimens were prepared. Prisms measuring $50 \times 50 \times 300 \mathrm{~mm}$ were cast for studying the degree of carbonation, and $150 \mathrm{~mm}$ cubes were cast for measuring the impermeability index, pore volume and compressive strength of concrete. The specimens were kept in their moulds for 24 hours and then they were demoulded and cured for 28 days either in air $(\mathrm{C} 1)$ or in water $(\mathrm{C} 2)$.

After curing, the prism specimens were immediately transferred to the carbonation chamber. Four sides, including the as cast surface, of the cube specimens were coated with a carbonation-resistant wax coating to allow $\mathrm{CO}_{2}$ to enter only from two parallel opposite sides of the cubes. The first side was used for air permeability measurements, whilst the other side supplied small samples to determine the pore volume. After the coating process the cube specimens were also placed in the carbonation chamber.

\section{Carbonation Test}

The carbonation chamber was developed by the author and is described in detail elsewhere [19]. The chamber contained a $5 \%$ concentration of $\mathrm{CO}_{2}$

At various intervals the prism test specimens were taken out of the carbonation chamber and a slice was sawed transversely using an electrically operated saw blade to expose an internal surface for carbonation depth measurements. The remaining part of each specimen was immediately returned to the carbonation chamber while the internal surface of the slice was sprayed with phenolphthalein solution to reveal the non-carbonated core. The depth of carbonation, as indicated by the pink colour, was measured on all sides of the slice and averaged for each specimen, then for all specimens from each mix. Three specimens from each mix were tested.

The cube specimens were also kept in the carbonation chamber. The air permeability of the uncoated surface of the cubes was measured at different time intervals. From the opposite uncoated surface small pieces were extracted for pore volume measurements. 


\section{Permeability Test}

Several techniques have been proposed for studying the air permeability of concrete. The most well known technique is the Figg Air Permeation Index [11]. However, this technique is not suitable for the present investigation as it assesses the air permeability of concrete 20 to $50 \mathrm{~mm}$ below the surface of the specimens. This depth is beyond the expected thickness of the carbonated layer and therefore the effect of carbonation cannot be measured using this test. Other tests involve preconditioning techniques which may alter the pore structure (e.g. Schonlin and Hilsdrof [12]), or measure the permeability of concrete to specific gases (e.g. Lydon and Odaallah [13]), or are difficult to set up (e.g. Parrott and Hong[14]). In this investigation, the vacuum test proposed by Dhir et al [15] was used to study the air permeability of the carbonated concrete surface since it does not suffer any of the shortcomings found in other techniques.

The vacuum test involves applying vacuum to the concrete surface using an air tight perspex cap (75 mm in diameter) clamped to the test specimen. After the vacuum pressure inside the cap reaches $100 \mathrm{kPa}(14.4$ psi) below atmospheric, the vacuum is turned off and the time required to regain a pressure of $10 \mathrm{kPa}(1.4$ psi) below atmospheric within the cap is measured. This time is called the impermeability index. Since air has to travel through the concrete to fill the area under the cap, the impermeability index is low (i.e. the time is short) for permeable concrete. A schematic diagram of the vacuum test is shown in Figure 1. Three cubes from each mix were used to determine the impermeability index.

\section{Pore Volume Test}

In this work the porosity was measured because of its influence on the transport properties. The relevant porosity is therefore the open porosity, i.e. the porosity which is accessible to moving fluids. Pore volume measurements are usually carried out using mercury intrusion porosimetry. However, Marsh et. al. [16] 
explained that the severe drying used to precondition samples for mercury intrusion porosimetry can damage the delicate and highly metastable microstructure of some types of concrete and penetrate previously closed pores. Similar findings have been reported by Parrott [17], Marsh et. al. [18] has shown that preconditioning the samples by solvent replacement and measuring the pore volume by Helium Pycnometry is a suitable technique for microstructure studies, because there is no damaging effect on the pore system. This procedure was used in this work.

Small pieces of the mortar test cubes from the carbonation chamber were broken from the exposed surface not used for permeability measurements. The pieces weighed a total of $1 \mathrm{gm}$. (0.035 ounce). Each cube, of the three placed in the carbonation chamber, provided a sample for pore volume measurements. To precondition the samples for pore volume measurements, each sample was placed in fresh propan-2-ol for seven days and then transferred to a fresh solution of the same composition for a further seven days. Then the samples were placed in n-pentane for a period of 14 days. Finally the specimens were dried in an oven at $30^{\circ} \mathrm{C}\left(86^{\circ} \mathrm{F}\right)$ for two days to remove the solvent. The volume of pores accessible to helium at twice atmospheric pressure was determined using a Beckman pycnometer. The pressure was applied for one minute before the reading was taken.

\section{RESULTS AND DISCUSSION}

\section{Results of the Carbonation Test}

The results of the carbonation test are shown in Figure 2. It can be seen that the carbonation depth vs. time relationships have shapes similar to the classical square root of time trend found by many previous investigators [5]. As expected the carbonation depths were higher for low strength and air-cured concrete. The open pore system of such poor quality concrete allows the diffusion of $\mathrm{CO}_{2}$ gas with limited restriction compared to that posed by the higher strength and water-cured samples 


\section{Results of the Permeability Test}

The results of the permeability test are shown in Figures 3 and 4. It can be seen from Figure 3 that the strength and curing of concrete are the main factors affecting the impermeability index. For example, the impermeability index for the high strength water-cured specimens (M2C2) was 3.7 times greater than that for the low strength water-cured mix (M1C2). The impermeability index for the former mix was also 2.3 times greater than its air cured counterpart (M2C1).

The first impression from Figure 3 suggests that carbonation leads only to a small increase in the impermeability index due to the precipitation of $\mathrm{CaCO}_{3}$ in the pore system of concrete. However, by plotting the percentage increase in the impermeability index against the carbonation time in Figure 4, a different picture is revealed. The figure shows that after 140 days of exposure to $\mathrm{CO}_{2}$ carbonation lead to approximately $37 \%$ and $4 \%$ increase in the impermeability index for Mixes M1 and M2, respectively. In other words, the effect of carbonation on the impermeability index was more pronounced for mix M1, i.e. the lower concrete strength. This may be explained by the fact that the carbonation depths for M1 were more than four times those for M2. Therefore, a larger segment of the M1 specimens suffered the pore blockage from carbonation. Air cured specimens (C1), after extended exposure to carbonation for mix M1 and at all stages of exposure for mix M2, showed a higher increase in the impermeability index compared to water cured $(\mathrm{C} 2)$ ones made from the same mix. This may be attributed to the fact that the degree of hydration has a significant effect on the volume of capillary pores which is the main factor affecting

permeability [3]. As a result, air cured samples would have more inter-connected channels available to be blocked by the carbonation products, and hence such specimens would exhibit a greater effect on permeability due to carbonation.

\section{Results of the Pore Volume Test}


The results of the pore volume test are shown in Figures 5 and 6. It can be seen from Figure 5 that the total pore volume accessible to helium is highest for low strength air cured concrete ( $\mathrm{MlCl})$. Before any exposure to $\mathrm{CO}_{2}$, the reduction of W/C ratio by $33 \%$ between $\mathrm{M} 1$ and $\mathrm{M} 2$ reduced the total pore volume by $192 \%$ and $100 \%$ for air and water cured specimens, respectively. This demonstrates the dramatic effect of reducing the W/C ratio on pore volume. On the other hand, water cured M1 and M2 specimens had $43 \%$ and $17 \%$ less pores than air cured ones, respectively. This shows that water curing is especially important in concretes with high water-to-cement ratios.

It can also be seen from Figure 5 that there is an initial drop in the pore volume due to carbonation, then the pore volume is reduced at a very slow rate. This may be explained by the fact that specimens for the pore volume test are always extracted from the surface of the concrete. Therefore, soon after being placed in the carbonation chamber, the tested specimens would be fully carbonated and hence the effect of carbonation on the pore volume would be measured at a very early stage of exposure to $\mathrm{CO}_{2}$.

Figure 6 shows the percentage reduction in the total pore volume due to carbonation. It can be seen that carbonation caused a reduction of 18 to $38 \%$ in the pore volume of the tested concrete. The reduction is greater for low strength air cured concrete again because this type of concrete is more prone to carbonation.

\section{Comparison Between the Effect of Carbonation on Permeability and Pore Volume}

By comparing Figures 4 and 6, an interesting observation can be made. Carbonation has resulted in an increase in the impermeability index of only $5 \%$ or less for the M2 mixes in spite of the fact that the total pore volume of these mixes was reduced by at least $18 \%$ after being exposed to $\mathrm{CO}_{2}$ for 140 days. This may be attributed to the fact that permeability is not a unique function of porosity and flow in concrete is restricted to distinct channels [20]. Usually, only the large capillary pores, greater than $0.1 \mu \mathrm{m}$ support fluid flow in concrete $[16,21]$. The volume of such pores is small in mixes with W/C below $0.55[21,22]$. 
Therefore, the permeability of the M2 mixes was initially low and it remained low with little possibility for improvement due to carbonation. However, the precipitation of $\mathrm{CaCO}_{3}$ in the pores did lead to a measurable effect on the total pore volume.

On the other hand, the eventual increase in the permeability of the M1 mixes was almost equal to the reduction in the pore volume due to carbonation. It may be argued that this concrete had a considerable percentage of large capillaries which were blocked by $\mathrm{CaCO}_{3}$ and hence the effect of carbonation on permeability was similar to its effect on the pore volume for Ml mixes.

\section{Other effects of carbonation}

The effects of carbonation are summarised in Table 2.

The first row shows the loss of alkalinity which has the most significant consequences for durability of reinforced concrete structures.

From the next two rows it may be seen that the most significant effect on the transport properties, which is similar to that on the electrical properties, is that durability tests give misleading results [23]. The electrical properties of concrete affect the corrosion of embedded steel because the corrosion can only take place if a current can flow through the concrete between the anodic and the cathodic regions [1]. Corrosion is therefore reduced when the resistivity is increased. Carbonation increases this resistivity by reducing the concentration of hydroxyl ions which are the main charge carries in hydrated cement paste [24]. The increase is substantial and has been shown to be proportional to the extent of the carbonation. Table 2 also shows that carbonation causes shrinkage and this may result in cracking [25]. This would affect durability adversely by facilitating the transport of aggressive species into the concrete.

\section{CONCLUSIONS}

1. Carbonation leads to a significant reduction in the permeability and porosity of concrete. 
2. This reduction is greatest in poor quality concrete.

3. Due to carbonation effects, concrete testing results on surface permeability and electrical properties may be misleading. 


\section{REFERENCES}

1. Illston J.M., Construction Materials, E\&FN Spon, 2nd. Ed. 1994.

2. Cabrera J.G., Claisse P.A. and Hunt D.N., A statistical analysis of the factors which contribute to the corrosion of steel in Portland cement and silica fume concrete, Construction and Building Materials, 1995, Vol.9, No.2, pp.105-113.

3. Neville A.M. and Brooks J.J. "Concrete Technology", Longman Group Ltd.,1990, 438 pp.

4. Papadakis V.G., Vayenas C G and Fardis MN. "Fundamental modelling and experimental investigation of concrete carbonation", ACI Materials Journal, 1991, pp 363 - 373.

5. Parrott L.J., "A review of carbonation in reinforced concrete", Cement and Concrete Association, 1987,369 pp.

6. Kasai Y., Matsui I., Fukushima Y. and Kamohara H. "Air permeability and carbonation of blended cement mortars", ACI SP - 79,1983, pp.435 - 451.

7. Dhir R.K., Hewlett P.C. and Chan Y.N., "Near - surface characteristics of concrete: prediction of carbonation resistance", Magazine of Concrete Research, 1989, pp 137 - 143.

8. Bilicik J. "Permeability of concrete as a method for calculating the life expectancy of reinforced concrete components", Proceedings of the International Conference on the Protection of Concrete, Dundee, 1990, 681 pp. 
9. Pihlajavaara S. E., "Some results of the effect of carbonation on the porosity and pore size distribution of cement paste", Materials and Construction, 1968, pp. 521 - 526.

10. Dewaele P.J. Reardon E.J. and Dayal R., "Permeability and porosity changes associated with cement grout carbonation" Cement and Concrete Research, 1991, pp. 441 - 454.

11. Figg J. W., "Methods of measuring the air and water permeability of concrete", Magazine of Concrete Researched 1973, pp 213 - 219.

12. Schonlin K. and Hilsdorf H., "Evaluation of the effectiveness of curing of concrete structures", ACI SP 100, 1987, pp.207 - 226.

13. Lydon F. and Odaalah M., "On surface relative permeability test for concrete", Construction and Building Materials, 1988, pp .102 - 105.

14.Parrott L.J. and Hong C.Z., "Some factors influencing air perrneation measurements in cover concrete", Materials and Structures, 1991, pp 403 - 408.

15.Dhir R.K., Hewlett P.C, Byars E.A. and Shaaban I.G., "A new technique for measuring the air permeability of near surface concrete", Magazine of Concrete Research, 1995, pp. 167- 176.

1 6.Marsh B.K., Day R.L., Bonner D.G. and Illston J.M., "The effect of solvent replacement upon the pore structure characterization of Portland cement paste", Proceedings RILEM / CNR Symposium on principles and application of pore structural characterization, Milan, 1983, Paper 003. 
17. Parrott L.J., "Novel methods of processing cement gel to examine and control microstructure properties", Philosophical Transactions of the Royal Society, London, 1983, pp. 155- 166.

18. Marsh B.K., Day R.L. and Bonner D.G., "Pore structure characteristics affecting the permeability of cement paste containing fly ash", Cement and Concrete Research, 1985, pp. 1027- 1038.

19. El Sayad H. I., "A study of some new carbonation resistant materials", Journal of the Egyptian Society of Engineers, N0. 4, 1996.

20. Nyame B.K. and Illston J.M., "Relationships between permeability and pore structure of hardened cement paste", Magazine of Concrete Research, 1981, pp. 139 - 146.

21. Mehta P. K. and Manmohan D., "Pore size distribution and permeability of hardened cement pastes", Proceedings of 7 th International Congress on the Chemistry of Cement, Paris, 1980.

22. Collins J. F., Derucher K. N. and Korfiatis G. P., "Permeability of concrete mixtures: Part 1: Literature Review", Civil Engineering for Practicing and Design Engineers, 1986, pp. 579 - 638

23. Browne R.D., Geoghean M.P. and Baker A.F., "Analysis of structural condition from durability results", "Corrosion of reinforcement in concrete construction" ed. Crane A P, Ellis Horwood 1983.

24 Claisse P.A., Properties and Performance of High Strength Silica Fume Concrete, PhD Thesis, University of Leeds, UK 1988.

25. ACI Committee 201, "Guide to Durable Concrete" ACI Journal, 1977, pp 573 - 609. 


\section{Table 1. Mix Proportions}

\begin{tabular}{|c|c|c|c|c|c|c|c|}
\hline MIX & $\begin{array}{l}\text { Ordinary } \\
\text { Portland } \\
\text { Cement } \\
\mathrm{kg} / \mathrm{m}^{3}\end{array}$ & $\begin{array}{l}\text { Water } \\
\mathrm{kg} / \mathrm{m}^{3}\end{array}$ & $\begin{array}{l}\text { Aggreg } \\
\mathrm{kg} / \mathrm{m}^{3} \\
20 \mathrm{~mm}\end{array}$ & $10 \mathrm{~mm}$ & $\begin{array}{l}\text { Sand } \\
\mathrm{kg} / \mathrm{m}^{3}\end{array}$ & $\mathrm{~W} / \mathrm{C}$ & $\begin{array}{l}28 \text { day } \\
\text { Compressive } \\
\text { Strength } \\
\mathrm{N} / \mathrm{mm}^{2}\end{array}$ \\
\hline M1 & 300 & 180 & 800 & 400 & 720 & 0.60 & 23.0 \\
\hline M2 & 400 & 180 & 400 & 400 & 600 & 0.45 & 50.0 \\
\hline
\end{tabular}

Conversion factors for imperial units:

1 pound-mass $/$ cubic foot $=16 \mathrm{~kg} / \mathrm{m}^{3}$

1 pound-force $/$ square inch $=0.007 \mathrm{~N} / \mathrm{mm}^{2}$

$1 \mathrm{inch}=25.4 \mathrm{~mm}$ 


\section{Table 2. The Effects of Carbonation.}

\begin{tabular}{|c|c|c|}
\hline Effect & $\begin{array}{l}\text { Consequences for durability of } \\
\text { structures }\end{array}$ & Consequences for durability testing \\
\hline Reduction of alkalinity & Causes reinforcement to corrode & $\begin{array}{l}\text { Detected with phenolphthalein } \\
\text { solution }\end{array}$ \\
\hline $\begin{array}{l}\text { Decrease in transport } \\
\text { coefficients }\end{array}$ & $\begin{array}{l}\text { Causes carbonation rate to } \\
\text { decrease. } \\
\text { Reduction of chloride and } \\
\text { sulphate transport may be } \\
\text { significant. }\end{array}$ & $\begin{array}{l}\text { Surface durability tests such as Initial } \\
\text { Surface Absorption will give } \\
\text { misleading indication of improved } \\
\text { durability. }\end{array}$ \\
\hline $\begin{array}{l}\text { Decrease in electrical } \\
\text { resistivity. }\end{array}$ & $\begin{array}{l}\text { Reduction in corrosion probably } \\
\text { not significant. }\end{array}$ & $\begin{array}{l}\text { Measurements of resistivity and rest } \\
\text { potential give misleading results. } \\
\text { Reliability of electrical chloride } \\
\text { migration tests could be affected. }\end{array}$ \\
\hline Shrinkage & Can cause cracking & \\
\hline
\end{tabular}


List of Figures:

Figure 1 Schematic Diagram of the Vacuum Test

Figure 2 Increase of Carbonation Depth with Time

Figure 3 Effect of Carbonation on the Impermeability Index

Figure 4 Reduction of Permeability as a Result of Carbonation

Figure 5 Effect of Carbonation on the Total Pore Volume of Concrete

Figure 6 Reduction in Total Pore Volume Due to Carbonation 


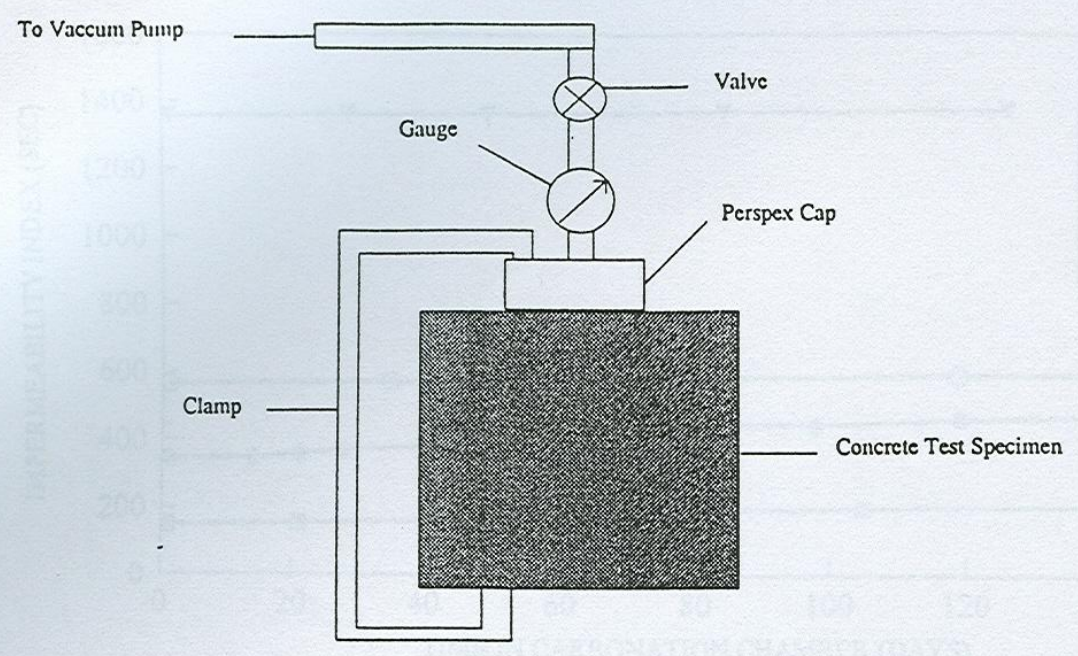

Figure 1 Schematic Diagram of the Vacuum Test

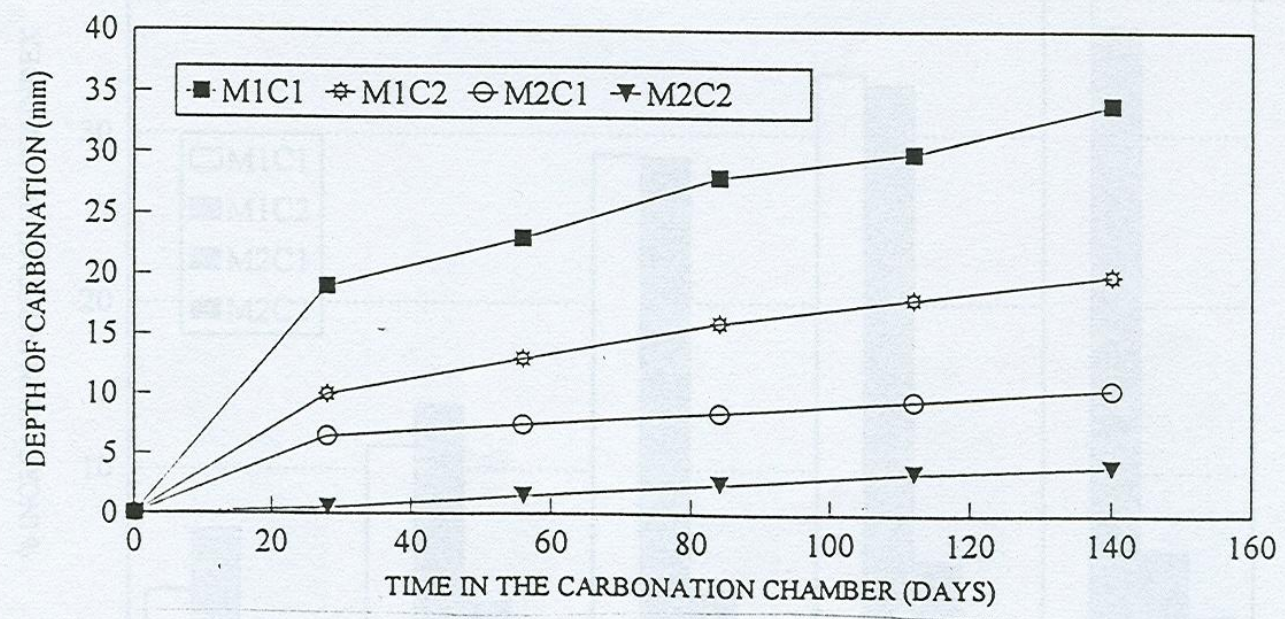

Figure 2 Increase of Carbonation Depth with Time 


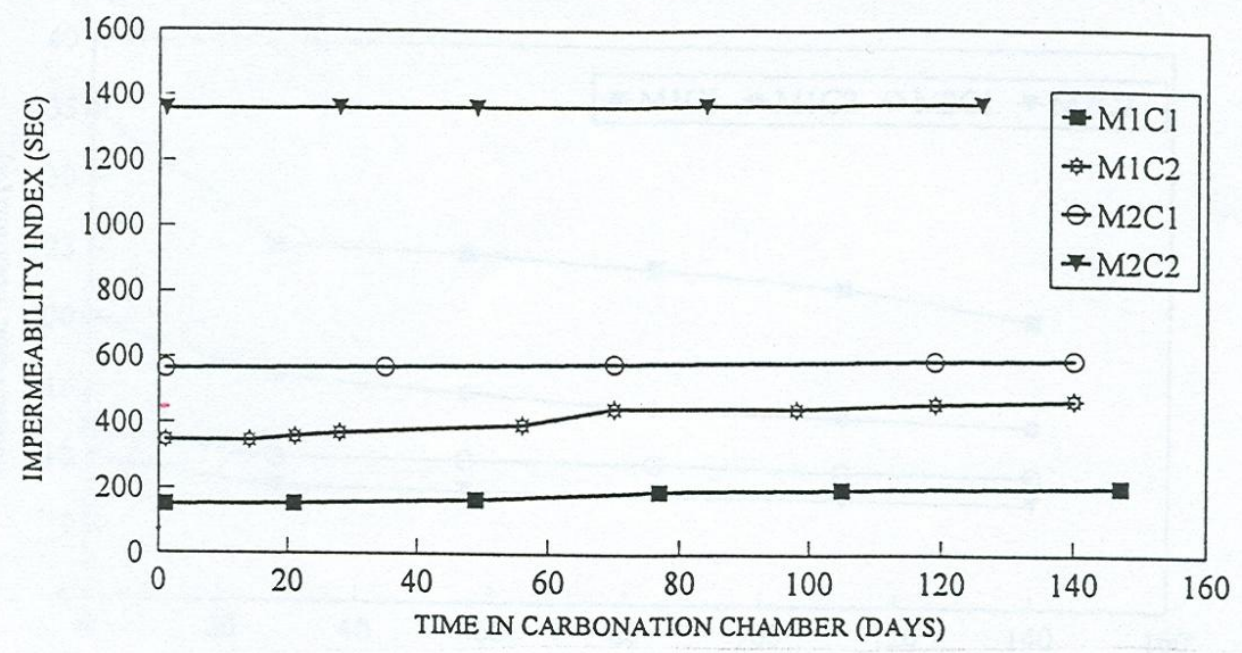

Figure 3 Effect of Carbonation on the Impermeability Index

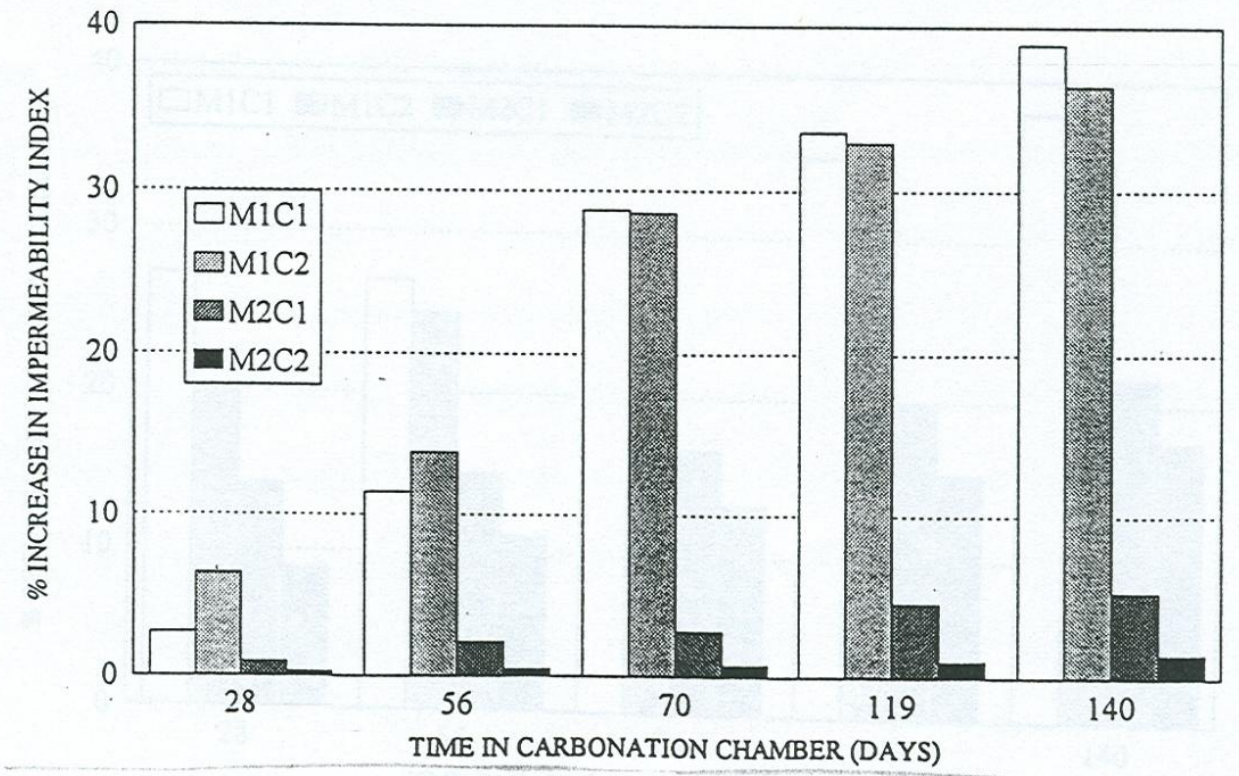

Figure 4 Reduction of Permeability as a Result of Carbonation 


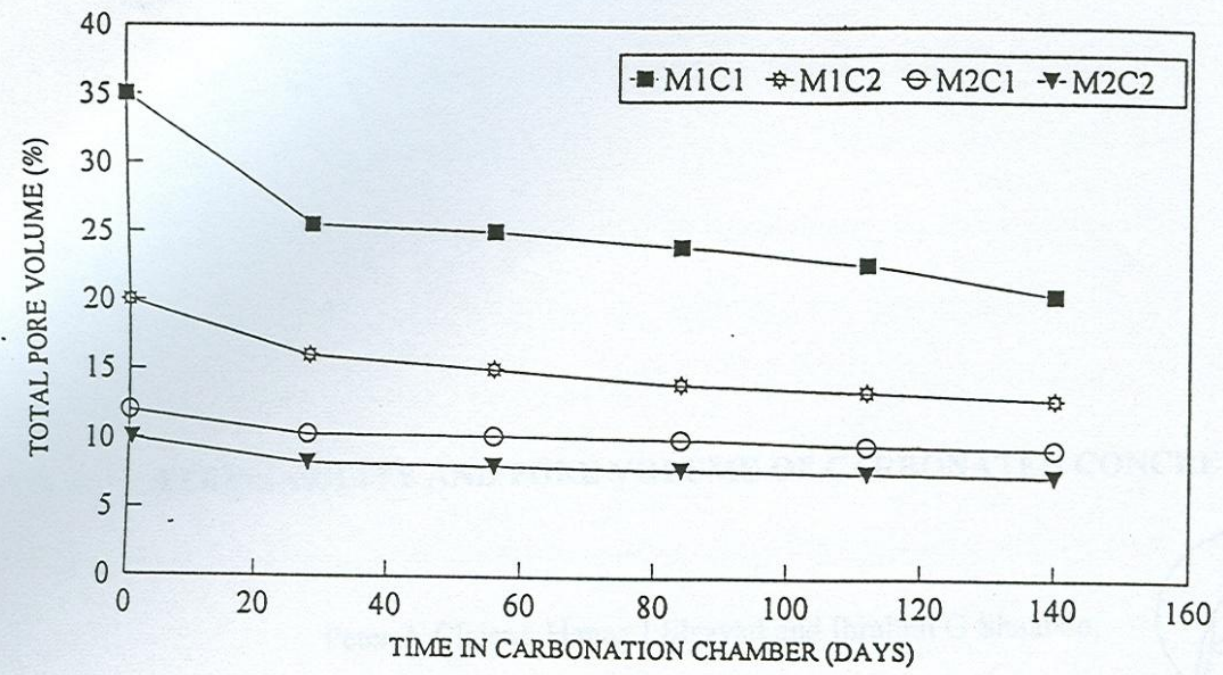

Figure 5 Effect of Carbonation on the Total Pore Volume of Concrete

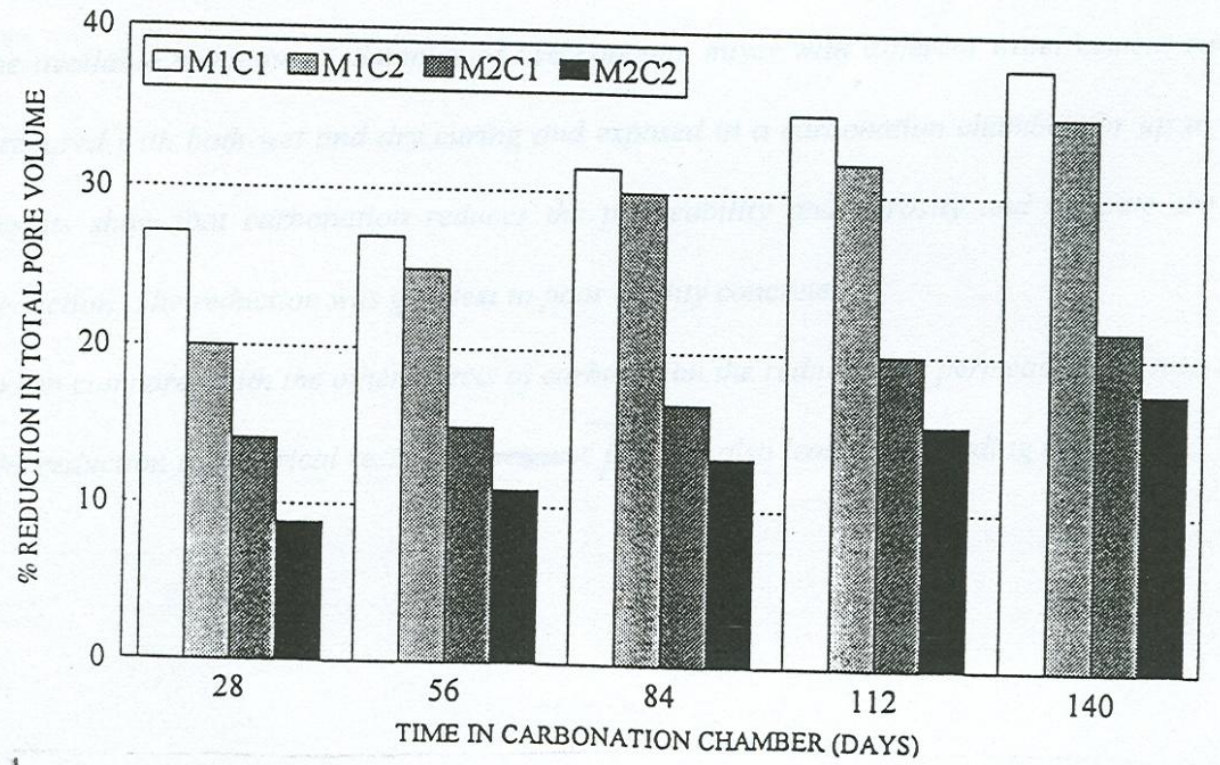

Figure 6 Reduction in Total Pore Volume Due to Carbonation 